using $\mathrm{SO}_{2}$. This dissolves in water to give $\mathrm{SO}_{3}{ }^{2-}$ ions, and it is observed that, when $\mathrm{SO}_{2}$ is bubbled through yellow $\mathrm{AuCl}_{4}^{-}$solutions, the solution goes colourless before precipitating solid $\mathrm{Au}$. One would automatically think that the colourless solution, which is fairly stable when basic, would contain the monovalent complex, $\mathrm{Au}\left(\mathrm{SO}_{3}\right)_{2}{ }^{3-}$, since $\mathrm{Au}(\mathrm{I})$ species tend to be colourless while $\mathrm{Au}$ (III) are more often coloured. However, examination of Figure 5 shows that with $\mathrm{SO}_{3}{ }^{2-}$ the trivalent complex $\mathrm{Au}\left(\mathrm{SO}_{3}\right)_{4}{ }^{5-}$ should be the more stable. In fact the UV spectrum of the gold sulphite solutions contains only peaks characteristic of $\mathrm{Au}$ (III) species, showing that the predictions of the $\mathrm{Au}(\mathrm{III}) / \mathrm{Ag}(\mathrm{I}) \mathrm{E}^{\circ} / \mathrm{E}^{\circ}$ relationship are correct.
In using all these predictions, one should bear in mind, of course, that one is looking at only one side of the coin-that, in addition to the thermodynamics of the situation, there are also the kinetics to be borne in mind. Thus, we may predict that a reaction is thermodynamically possible, but it may happen so slowly as to be of no importance.

\section{Acknowledgement}

This paper is published by permission of the DirectorGeneral, National Institute for Metallurgy.

\section{References}

1 M. J. N. Pourbaix, 'Atlas D'Equilibres Electrochimiques', Gauthier-Villars, Paris, 1963

2 R. D. Hancock and N. P. Finkelstein, Inorg. Nucl. Chem. Letters, $1971, \mathbf{7},(5), 477-484$

\title{
The Electrical Resistance of Vanadium-Gold Alloys
}

It is now just IIo years since Matthiessen (I) summarised his conclusions on the electrical characteristics of metals and alloys. Their resistance, he suggested, was the sum of a "thermal" resistance, unaffected by the presence of impurities, and of a "temperature independent" resistance caused by the presence of impurities or intentional alloying additions. This beautifully simple idea explained why the alloys of highest electrical resistance also had the lowest temperature coefficients, and precision resistance alloy development was thereby considerably facilitated.

Vanadium increases the resistivity of gold more rapidly than any other single alloying addition, and the primary solid solutions thus formed are strong, ductile, and readily drawn into fine wire. By adding small quantities of palladium to these binary solutions, $\mathrm{Dr}$ F. Sperner of Heraeus (2) has recently developed some very valuable alloys which combine a high resistivity with stability, low thermal e.m.f., and a temperature coefficient of only a few p.p.m. per ${ }^{\circ} \mathrm{C}$. In view of these practical implications, therefore, the results of a recent attempt to interpret the electrical characteristics of vanadium-gold alloys in terms of Matthiessen's original conception become of particular interest.

This work, carried out at the University of Sussex, (3) was part of a continuing programme concerned with the effect of $3 \mathrm{~d}$ transitional impurities upon the resistivity of gold. The alloys investigated contained respectively 2.0 and 0.8 atomic per cent of vanadium, such low concentrations satisfying the requirements of electronic band theory. Resistivity measurements were made at narrow intervals over the temperature range 0.5 to $273 \mathrm{~K}$. The high excess resistivity of the alloys, (i.e. the difference between the resistivity of the pure metal and that of the alloy at the same temperature) was found not to be constant as Matthiessen would have suggested. While moderately steady at temperatures below $50 \mathrm{~K}$, it then began to fall rapidly and almost linearly with rising temperature, thus compensating for the increasing resistivity of the gold and accounting in part for the anomalously low temperature coefficient of these solid solution alloys.

Earlier work on gold alloys containing small quanti- ties of titanium, manganese, iron, cobalt and nickel (4) had shown that the resistivity results could be successfully interpreted in terms of a two band electronic model which allowed the effect of temperature on those factors which cause phonon and impurity scattering to be quantitativly established. Similarly varying coefficients were found to be applicable to vanadium-gold alloys, and were used to calculate the resistivity which could reasonably be caused by alloying effects. These calculated resistivities were very much lower than the total excess resistivities which were measured, and the discrepancies between theoretical and experimental results were found to be roughly proportional to the concentration of vanadium which was present. The authors conclude that alloying effects account for only part of the total resistivity of vanadium-gold alloys, and that departures from Matthiessen's rule increase rapidly and become very significant as the wires warm up to room temperature.

The practical metallurgist might well have expected this conclusion, as all the standard resistance alloys such as Manganin, Constantan, and Nichrome are anomalous in the Matthiessen sense. Their departures from the ideal state are, however, fairly minor. Vanadium-gold alloys deviate from the straight and narrow additive path very strongly indeed, and Ford and his coworkers demonstrate very convincingly that their high electrical resistance can only be partly accounted for by the two-band electronic alloy model. One is left to conclude that some unknown and powerful resistive component resides in these transition metal solutions and that a fuller understanding of the mechanism involved might result in the rapid development of a new generation of electrical resistance alloys.

\section{References}

1 A. Matthiessen and C. Vogt, Trans. Roy. Soc., 1864, 154, 167

2 F. Sperner, Gold Bulletin, 1973, 6, (3), 72

3 P. J. Ford, T. E. Whall and J. W. Loram, 7. Phys, F: Metal Phys., 1974, 4, (2) 225

4 T. E. Whall, P. S. Ford and J. W. Loram, Phys, Rev. B., $1972,6,3501$ 